\title{
Organized complexity of the urban object
}

\author{
Mark David Major*a (D) \\ Raya M. Atour ${ }^{\mathrm{b}} \mathbb{C}_{\mathbb{D}}$ \\ Heba O. Tannous ${ }^{\mathrm{c}}$ (D)
}

\begin{abstract}
Over a half-century, space syntax has proven resilient as a theory and method for describing and analyzing the built environment from dwellings and complex buildings to cities. The paper briefly discusses resilience as a concept in the built environment and the foundations of space syntax itself. We summarize the body of the theoretical thinking in space syntax - laws of the urban object, generic function, principles of centrality and linearity, the design method of spatio-formal processes, and laws of spatial emergence-convergence - before offering a new hypothesis about laws of spatial conservation and spatial optimization at work in the built environment. The latter builds on Conroy-Dalton's (2001) ideas about angularity and the conservation of linearity in movement. Both could provide an essential bridge with Carvalho and Penn's (2004) concept of self-similarity in settlements, which relates to Batty and Longley's (1994) notions of fractal cities. We argue the hypothesis of conservationoptimization defines the conceptual framework for the progressive and regressive practice of urban planning in settlements. We illustrate this theoretical discussion by demonstrating the resilience or replication of previous space syntax findings, and by drawing on new research about the history, spatial structure, and neighborhood logic of Metropolitan Doha.
\end{abstract}

Keywords: cities, resilience, scientific method, space syntax, urban

\section{Introduction}

The most accepted definition of 'resilience' in the disciplines of the built environment too often promotes the subject as the sole, exclusive purview of specialists, especially the urban planning field. Davoudi (2012) defines this narrow definition as engineering resilience or the ability of a system to return to a steady-state or equilibrium after a significant disturbance, usually because of a natural or human-made disaster, whereby system means a city, economy, or usually both. The basis for Holling's $(1973,1986)$ original definition was "the faster the system bounces back, the more resilient it is (with an) emphasis on return time" (Davoudi, 2012; 300). However, common sense tells us that resilient or resilience must have more expansive and inclusive terms if we do not want to introduce troubling ethical and moral paradoxes for professionals into the practice of architecture and town planning (Major \& Al-Nabet, 2018). A more inclusive definition should include both design and planning, but also techniques based on scientific method: observation, hypothesis, data collection, testing and refinement, and theory. Classic scientific method is an 
approach that assigns great value to resilience through replicating results and, in the absence of the former, repudiating theories. Resilient method leads to sustainable design, offering adaptability for technological evolutions and a source of inspiration for the places where we live, work, and play. At its core, it means understanding the present and past to design and build a more beautiful and livable future for this planet's natural and human-made environments.

For a half-century, space syntax has been a resilient set of objective techniques for representing Page | 2 and measuring architectural and urban space using topological measures based on principia of network science (Benedikt, 1979; Hillier and Hanson, 1984; Hillier et al., 1987a-b; Hillier, 1989; Hillier et al., 1993; Penn et al., 1998; Turner et al., 2001; van Nes \& Yamu, 2021). Today, space syntax is an international research program of academics and practitioners composing hundreds, even thousands of people, in more than forty countries worldwide, especially in Europe, South America, and Southeast Asia. Space syntax began with Bill Hillier, Julienne Hanson, John Peponis, Alan Penn, and many others, who were thinking, researching, testing, and refining their ideas about the built environment in the 1970s and 1980s at The Bartlett at University College London. The philosophy of space syntax relies on two clear ideas for investigating the spatial networks of architectural and urban space: scientific method and recognition that our built environment is both a product of society and an influence on society (Hillier and Hanson, 1984; Hillier, 1996; Hanson, 1998; Major, 2018). Although the latter recognition might open doors to deterministic dilemmas and many philosophical dialogues on the influence of which on which, the scientific method keeps space syntax research fixed in a manner that prevents it from falling into direct logical fallacies. Space syntax relies on the probable behavior of aggregate populations in space, not determinism.

Hillier and Hanson (1984) stake their ground from the opening words of The Social Logic of Space. They quote French archaeologist Andre Leroi-Gourhan (1964) "Le fait humain par excellence st peut-etre moins la creation de l'outil que la domestication du temps et de l'espace, c'est-a-dire la creation d'un temps et d'une espace humaine (The human fact par excellence is perhaps less the creation of the tool than the domestication of time and space, that is to say the creation of a human time and space)" (Hillier \& Hanson, 1984; v). In the early 1940s, Leroi-Gourhan (1943 \& 1945) hypothesized the concept of technical tendencies, which are universal technical dynamics operating independently of ethnic groups that are nonetheless the only forms realized through these tendencies. He argues this realized form is a technical fact. He developed this idea into a general theory about the relation between the technical as universal tendency and the ethnic as differentiated specific. We can detect the origins of Hillier and Hanson's ideas about architecture and urban space in Leroi-Gourhan's theories about the difference between technical universalities and ethnic specifications.
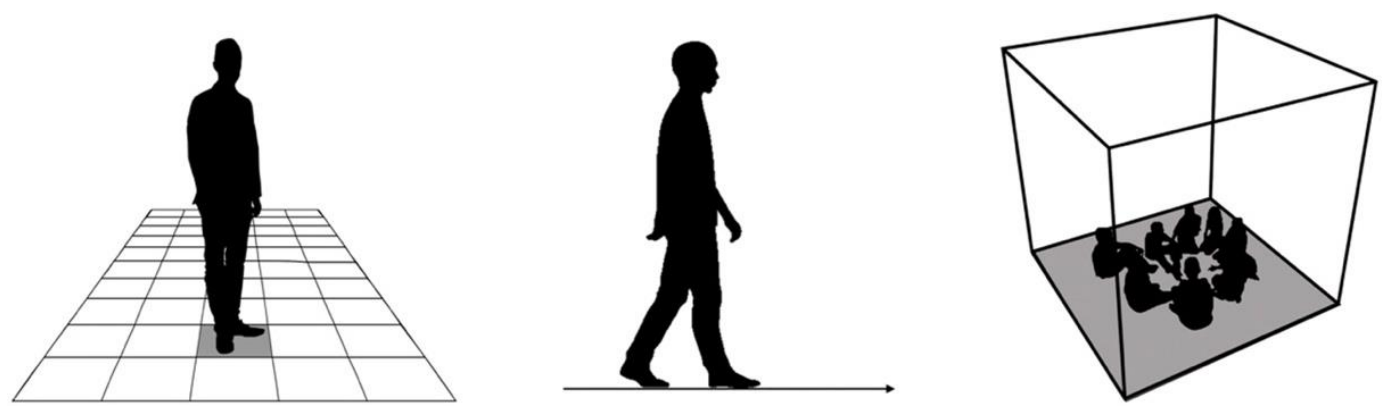

Figure 1 Representations of (left to right) a point, line, and convex space in space syntax (Source: Tannous et al., 2021).

The paper briefly demonstrates the resilience of the space syntax technique with a review of critical concepts, methodological grounding, and theoretical findings, emphasizing one of the most resilient objects in human history: the city. We layer this review with various well-established and new representations and research findings, respectively. Many focus on the Middle East and, specifically, the city of Doha in the State of Qatar. A comparison of design methods in ortho-radial 
grids from the highly geometric, regular grids in the United States to the more deformed grid layouts of the Middle East serves as an essential baseline for this review. This grounding in space syntax is necessary before introducing a new hypothesis about laws of spatial conservation and optimization at work in the urban grid of cities, which can provide an additional layer to many Hillierian concepts about form and function in urban space.

Page | 3

\section{Technique and Method}

Space syntax representations are often plan-based, using easily understood constraints of the built environment for the most general human uses such as movement, occupation, and visibility. Such constraints are essential because we are forward-facing, bipedal creatures bound by gravity everywhere on the surface of this Earth (Hillier, 1996; Major, 2018) (Figure 1). A point in space is the most straightforward notion of building a geometry with only position and no size. The number of points in any space will be infinite without a resolution. Defining the bounds of space and 'size' for all points resolve this issue, such as using the average standing area of a normal human being $(0.28 \mathrm{~m} 2)$ (Turner et al., 2001). Movement tends to be linear, so the axial line or line of sight and access (e.g., axis) represents an idealization. A line is a set of points having no width or depth, only a length. The matrix of longest and most strategic (i.e., fewest) axial lines completely covering all spaces of an urban environment as defined by its built surfaces (walls or facades) is the axial map (Hillier and Hanson, 1984). The axial map is the most common reference to a 'space syntax model' for forecasting movement flows in the urban environment with usually $60 \%-80 \%$ accuracy (Hillier et al., 1993; Penn et al., 1998). The occupation of space tends to be convex, where everyone can see and be seen by everyone else, such as a group of people gathered in a circle or a room. Convexity is 'the quality or state of being convex' (Source: Oxford English Dictionary). All points are visible to all other points in a convex space. The convex map composes all convex spaces in a built environment, which tends to be more helpful for building analysis (Hillier et al., 1987; Hillier, 1996; Hanson, 1998). The potential for seeing and moving is a visual field, all visible and accessible space from which we might see or move as defined from a point or set of points such as a point, axial line, or convex space (Benedikt, 1979) (Figure 2). A visibility map is the matrix of all visual fields from a gridded set of points to all others in a built environment (Turner et al., 2001). Space syntax uses combinations of these simple descriptions - point, line, space, field - to create sophisticated representations of the built environment.
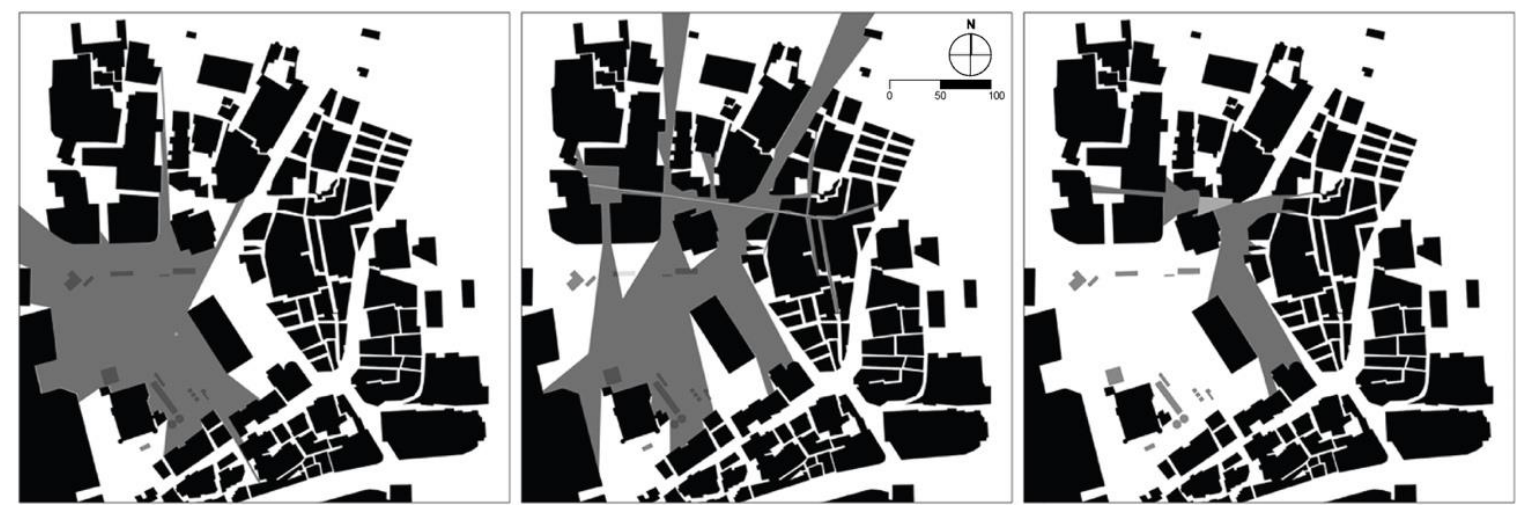

Figure 2 Visual fields (in dark grey) from (left to right) a point, line, and convex space (in light grey) in the layout of Souq Waqif in Doha, Qatar (Source: Authors/Tannous et al., 2021). ${ }^{1}$

Space syntax researchers measure the matrices of these representations - point, line, convex space, visual field - using topological graph theory to quantify the configurational relationship of each to all others and vice versa or within a set range. Configuration is a network system where local changes have global effects across that system to varying degrees, dependent on system size

\footnotetext{
${ }^{1}$ Plan elements in the large open plaza towards the lower-left represent impediments to movement but not visibility, i.e., a typical human being sees over the top of these elements.
} 
relative to the significance of the change itself (Hillier, 1996). We can illustrate the basics of configuration using a simple example from Hillier (1996) (Figure 3). We can understand the basics of measuring configuration using topological graph theory where two objects labeled $A$ and $B$ similarly relate until introducing a third object named $C$, such as the surface of the Earth. All three objects vary configurational relationships based on connection or permeability in the justified graph where we represent the object as a node and their relation as a line. We can measure such a relationship for various parameters based on mean depth within - borrowing a phrase Baudrillard (1968) popularized - the system of objects. The key is that configurational measures offer a scientific basis to implicate or dismiss the designed spatial network as a factor for social, functional, or cultural inputs or outputs.

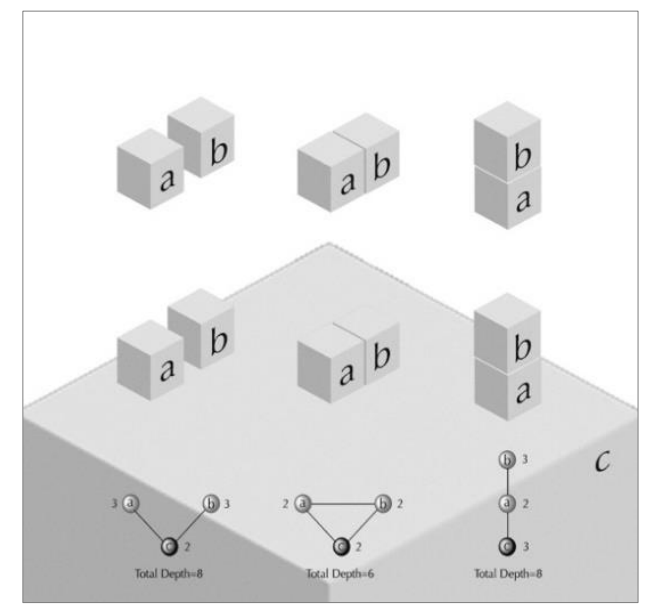

Figure 3 The basics of configuration (Source: Tannous et al., 2021 and Major, 2018 after Hillier, 1996).

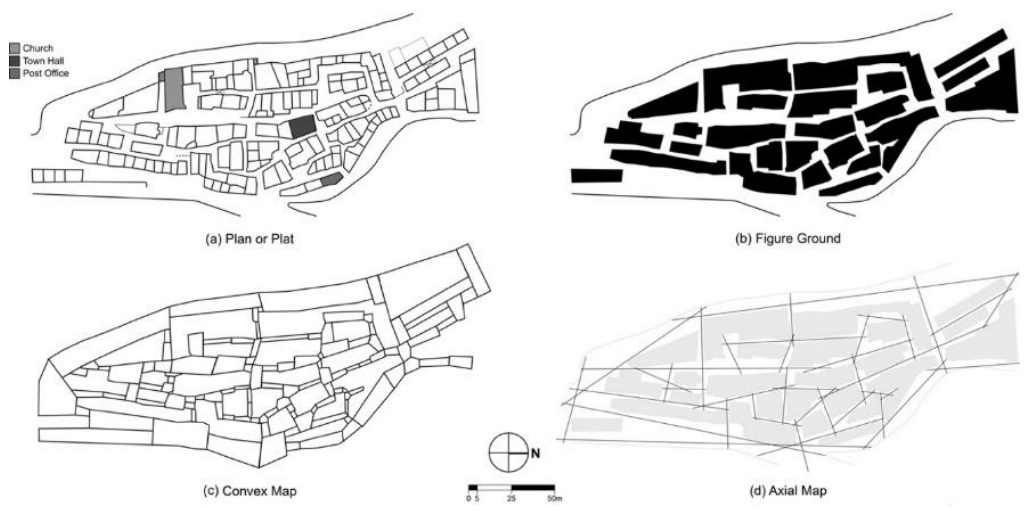

Figure 4 Space syntax modeling of the layout of Gassin in the Var region of France circa 1980 based on the (a) plan/plat, (b) figureground with defined bound, blocks in black, and space in white, (c) convex map, and (d) axial map (Source: Tannous et al., 2021 after Hillier and Hanson, 1984).

Urban analysis in space syntax usually relies on drawing an axial map of the open space structure based on a plan to analyze its spatial configuration (Hillier and Hanson, 1984; Hillier, 1989) (Figure 4). The best results usually require a plan or plat accurately depicting all building footprints in a settlement. We can also represent the open spaces using the fewest and fattest set of convex spaces as defined by the facades of the built environment necessary to encompass the entire settlement in the convex map. We might double-check the one-dimensional mapping of the axial map for connecting all two-dimensional representations of convex spaces by overlaying one map on top of the other. Most people skip this stage unless they research the design or use of specific convex spaces in a settlement such as a public plaza or square. They immediately draw the most extended and fewest axes to pass through and encompass the open space structure of the entire settlement to create an axial map. Best practice usually suggests beginning with the most extended lines, then the shortest lines, and concluding with lines of intermediate length connecting between 
the two extremes of length.2 Using a figure-ground representation with all built forms in black often assists this process. Once the axial map is complete, computer software processes the map to analyze the system of relations between the lines. Hiller and Hanson (1984) argue the relation of all representations in any system is measured based on two essential properties: symmetry and asymmetry/distribution and non-distribution. It means the degree to which spaces compose shallow rings of circulation or deep sequences of trees in the underlying topological graph.

\section{Laws of the Urban Object}

Hillier and Hanson (1984) understood that others might misconstrue space syntax as an esoteric technique without general principles applicable to the built environment worldwide. They set about deriving general principles of space based on their research findings, colleagues, and students at UCL, especially settlements (Hillier \& Hanson, 1984; Hillier, 1989, 1996, 1999a-b, 2002; Hillier \& Vaughan, 2007). Such principles must apply to the design and planning of the built environment based on - but thriving in the explicit absence of - space syntax technique (Major \& Donegan, 2020). It is impossible to summarize the knowledge base of findings deriving from space syntax in a single paper. A recent textbook about space syntax in urban design even falls short of comprehensive for brevity's sake (van Nes \& Yamu, 2021). Nonetheless, these general principles have been helpful and resilient. Papers on hundreds of research topics from many reputable institutions globally support them and the application of space syntax in successful, real-world projects over the last 30 years, beginning with the Foster \& Partners' King Cross masterplan in 1988 (Major, 2018).

Hillier (1989) argued three general laws govern the urban object. First, Type 1 laws govern its generation. Second, Type 2 laws govern its effect on urban function and vice versa. Finally, Type 3 laws govern its influence on society in generating a distinctive spatial culture. We can view Type 2 laws (practical and socioeconomic function) as the critical mediator between Type 1 (technical tendencies of form and space) and Type 3 (ethnic or cultural specifications) laws (Major, 2018). A city is never only one thing but a dynamic synthesis of all three, which gives rise to what is allocentric ('common to all') and egocentric ('unique to each') about settlements (Carvalho \& Penn, 2004). Hillier's (1989 and 1996) most critical theoretical breakthroughs based on space syntax involve Type 1 laws giving shape to and being shaped by Type 2 and Type 3 laws. His ideas about the urban object appear to directly build on Lefebvre's (1974) ground-breaking argument regarding cities and space production. Lefebvre (1974) argued that space is a product of complex 'social structures' - physical, social, and mental spaces - as types, respectively, relating to Hillier's (1989) later three laws of the urban object (Salama \& Wiedmann, 2013).

It includes what Hillier (1996) defined as "generic function, by which means the spatial implications of the most fundamental aspects of human use of space, that is the fact of occupation and the fact of movement" (5-6). Hillier (1996) detailed this concept specifically for buildings, but Major (2018) argues that generic function is just as applicable for settlements, if not more so. In The Syntax of City Space, Major (2018) discusses how topographical conditions generate previous arrangements in space, making some locations better suited for human settlement than others. Site selection is the first conscious act of design in town planning. It rarely occurs in an intellectual vacuum, if ever (Major, 2018). In settlements, generic function means movement and the fundamental human requirements of occupation, e.g., water, food, and shelter. We do not need to build to move. We need to move to build and occupy a space. Water, food, and shelter are basic requirements to sustain our occupation of a space on the surface of the Earth (Major, 2018).

Hillier (1996) outlined other concepts with broad applicability for the built environment, i.e., the principle of centrality and axiality. The principle of centrality is the most internally integrating or

\footnotetext{
2 If the researcher does not use the auto-generation functionality of space syntax software. Auto-generation still requires careful review and correction of the axial map.
} 
accessible shape is a circle. Hillier (1996) refers to this principle as the Law of Compactness. The principle of axiality is the most externally integrating or accessible shape is a line. We can refer to this as the Law of Linearity, though Hiller never explicitly does so (Hillier, 1996; 267-69; Major, 2018) (Figure 5). The most recognized form of these laws at work in buildings are room and corridors, respectively. In settlements, it is blocks and streets (Figure 6). As Jacobs (1961) observed, elongated urban blocks deter activity and walkability, whereas smaller ones promote the opposite, primarily blocks square-ish shape adhering to Hillier's (1996) Law of Compactness (Major, 2018; Major \& AlNabet, 2018).

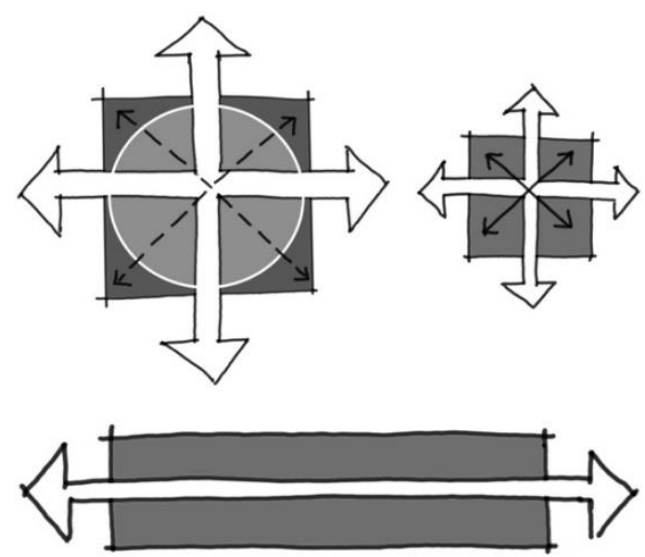

Figure 5 (top) Sketches illustrating in simple terms the principle of centrality or Law of Compactness and (bottom) the principle of axiality or Law of Linearity (Source: Authors, original skteches by Heba O. Tannous).

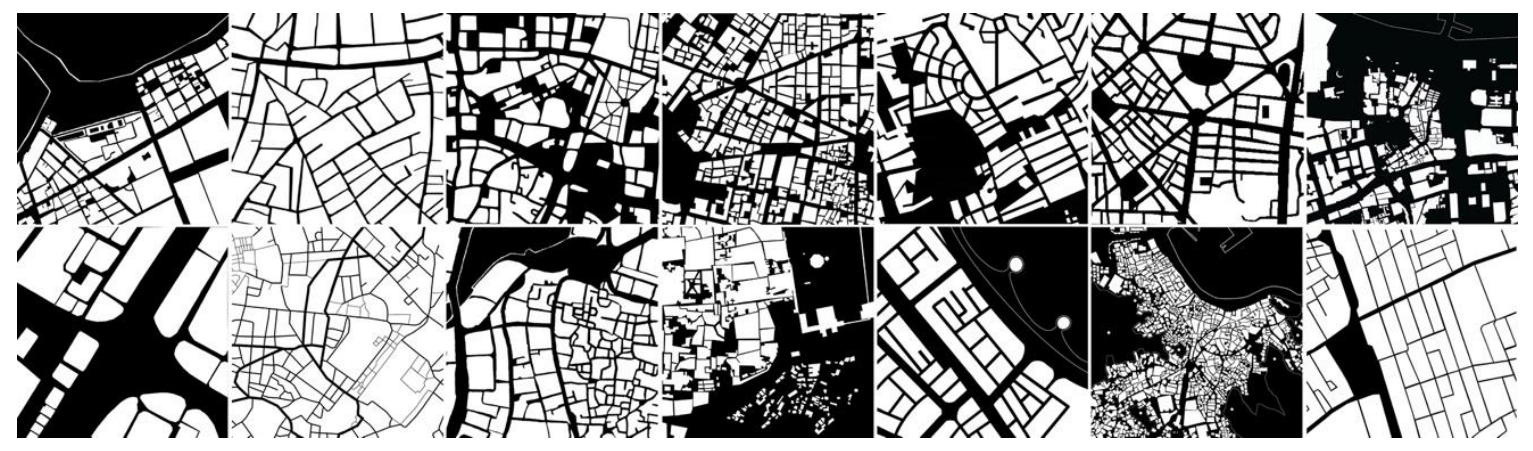

Figure 6 Figure-ground representations of one (1) square kilometer $\left(\mathrm{km}^{2}\right)$ area of urban fabric oriented north to a set scale in: (top, left to right) Alexandria, Egypt; Amman, Jordan; Beirut, Lebanon; Cairo, Egypt; Casablanca, Morroco; Damascus, Syria; Doha, Qatar; and (bottom, left to right) Dubai, UAE; Istanbul, Turkey; Jeddah, Saudia Arabia; Jerusalem; Kuwait City, Kuwait; Muscat, Oman; Riyadh, Saudi Arabia (Images: Authors/ARCT 210/DAUP-CENG-QU).

Finally, Hillier (1996) argued that cities adhere to laws of spatial emergence and convergence. By emergence, Hillier (1996) means predictable "global spatial effects" arising from purely "local physical moves" in the design of the urban grid (5). What we design has predictable effects on the spatial network of settlements. It must: otherwise, what is the point of hiring built environment professions? By convergence, Hillier (1996) means "processes whose rules... converge on particular global types which may vary in detail but at least some of whose most general properties will be invariant." It means effects on urban spatial networks are more similar than different in settlements, usually converging on the ortho-radial grid type worldwide to one degree to another (245) (Figure 7). Major (2013 and 2018) identifies the design methods characterizing these purely 'local physical moves' resulting in readily predictable spatio-formal processes (Major et al., 2019). These spatio-formal processes are expansion, block manipulation (upsizing and subdividing), deformation, extension, marginal separation by linear segregation, and discrete separation by linear segregation. The last is a common consequence of suburban sprawl, especially in the American experience (Figure 8). Major (2013 and 2018) argues these processes are allocentric, arising from Type 1 laws shaping urban form. They vary in egocentric terms from settlement to 
settlement and region to region over time only for metric scale and geometrical articulation as mediated by Type 2 (socioeconomic) and Type 3 (cultural) laws of the urban object (Major et al., 2019). However, geometric order has the benefit of making the process effect of these formal design methods on urban space readily apparent to the naked eye (Major, 2013 and 2018).
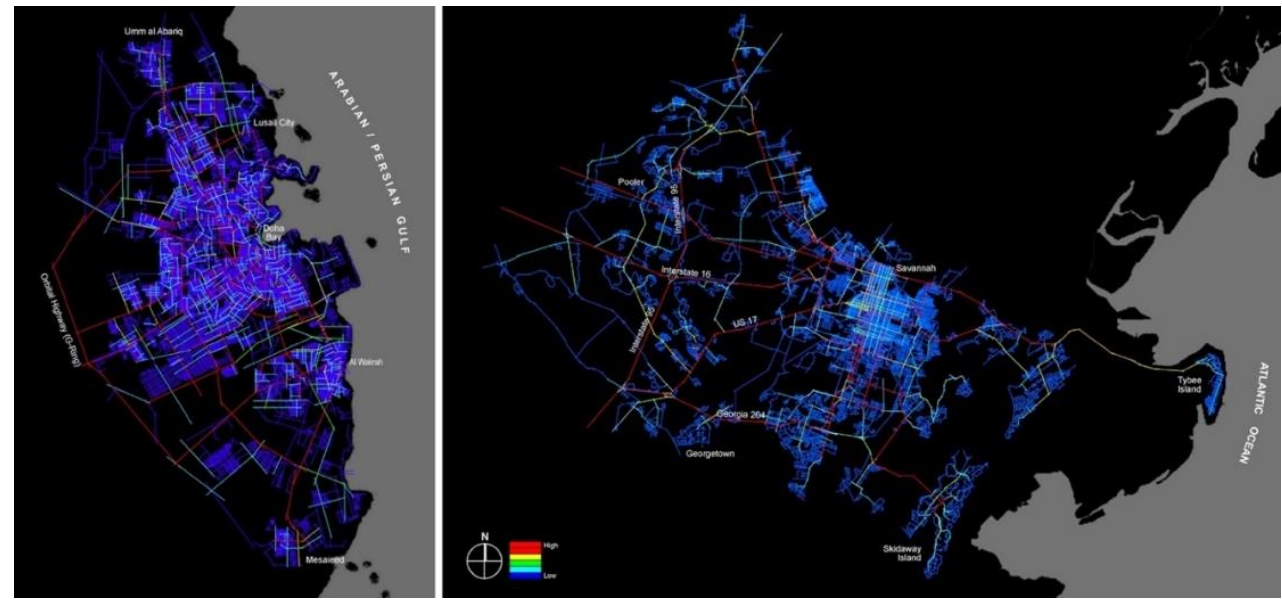

Figure $7 \mathrm{Global}$ choice in the axial map of (left) Metropolitan Doha, Qatar in 2020 and (right) Metropolitan Savannah/Chatham County, Georgia USA in 2019 (Images: QUCG-CENG-20/21-1/Major, 2020). Note: Not set to common scale.
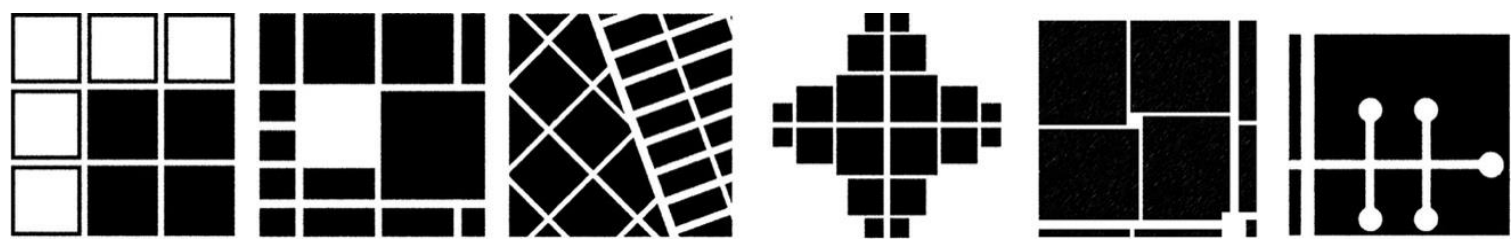

Figure 8 Representations of the most common design methods with predictable spatio-formal process effects in shaping the urban pattern: (from left to right) expansion, block manipulation, deformation, extension, marginal separation, and discrete separation (Source: Major, 2013, 2018 and Major et al., 2019).

\section{Laws of Spatial Conservation and Optimization}

There is a demonstrative resilience to Hillier and Hanson's (1984) thinking about the urban object through the replication of results by numerous practitioners and scholars using space syntax theory in settlements across the world; too many to briefly recount here (van Nes \& Yamu, 2021).

In the case of Doha, the replication of results includes a well-defined, deformed wheel spatial structure connecting from the Old Doha to the expanding urban edges of the city, identification of a local area effect in the second-order measure of Synergy (global vs. local integration) for all internal routes of Souq Waqif ('standing market') in the oldest historic area of the city, and evidence of urban centrality at work in the composition of the urban spatial network to effectively maintain the shallowness of Souq Waqif within this emergent spatial structure over time. For example, Souq Waqif encompasses only $0.19 \mathrm{~km} 2$ excluding the perimeter streets, but the catchment contour map within three directional changes is $22 \mathrm{~km} 2$, extending 2-4 kilometers $(\mathrm{km})$ to the west, southwest, and south. Using Hillier's (1999b) terminology, the 'spikey potato' catchment contour map of Souq Waqif represents a 116-to-1 ratio compared to its actual size. It occurs all in a manner previously described by Hillier, Hanson, and many others found in other cities worldwide (Hillier \& Hanson, 1984; Hillier, 1996 and 1999a-b; Major, 2018) (Figure 9 and 10). 

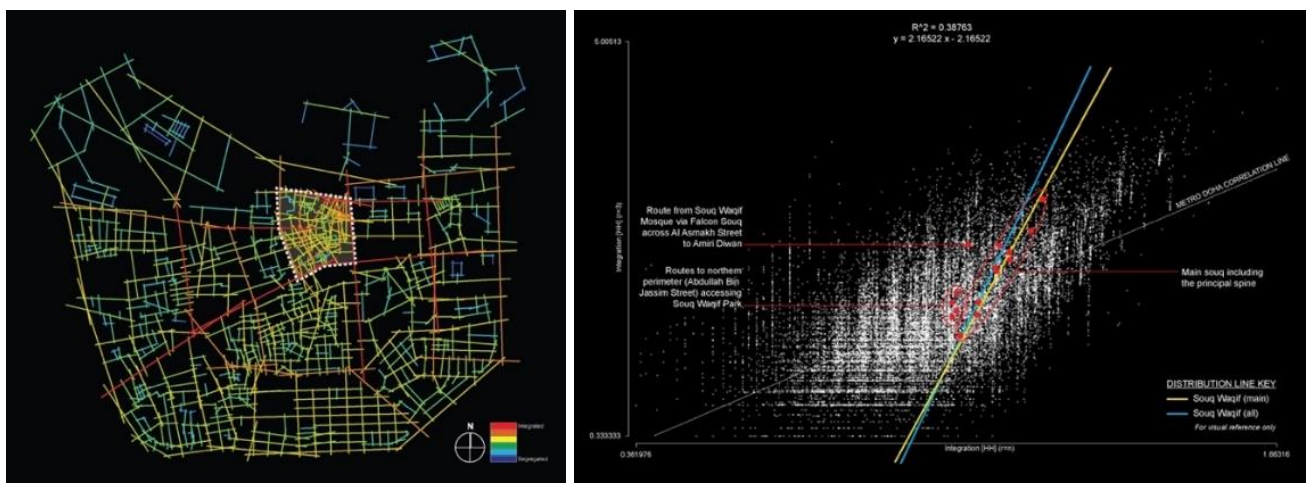

Figure 9 (left) Space syntax model of the pattern of local integration ( $r=3$ ) within the C-Ring Road in Doha in 2020 and (right) Local Area Effect for the principal routes of Souq Waqif (outlined in white in the axial map to the left and below) for Synergy (global v. local integration) within the urban spatial network of Metropolitan Doha (Source: QUCG-CENG-20/21-1/UREP25-002-5-001).

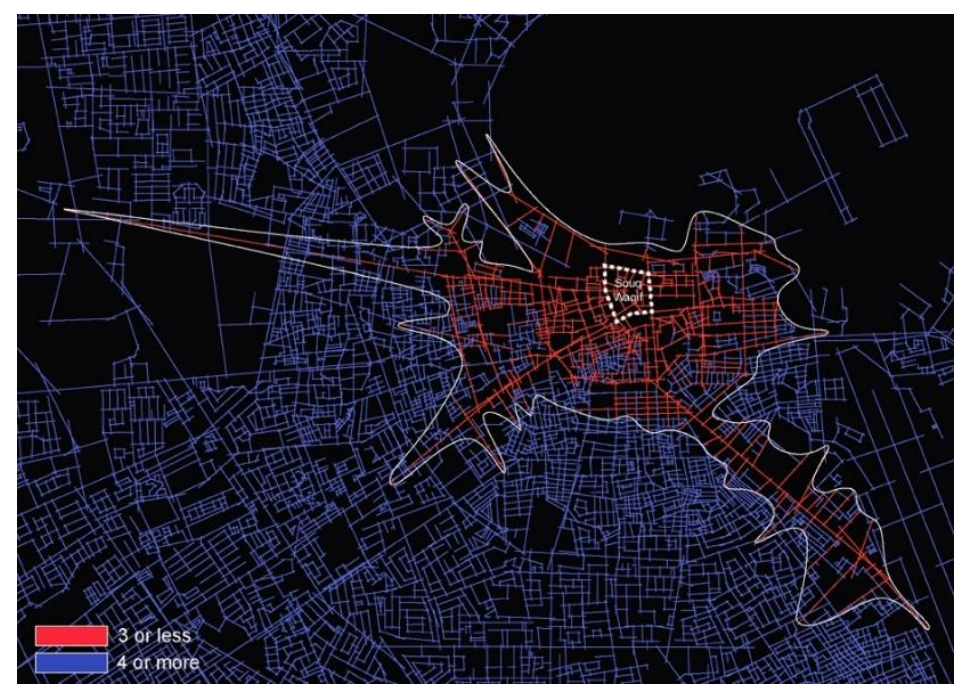

Figure 10 Urban centrality of Souq Waqif (outlined in dotted white) represented in the catchment contour map on all routes, represented as axial lines, within three changes of direction from the principal routes excluding the perimeter streets (Source: QUCG-CENG-20/21-1/UREP25-002-5-001).

Despite the resilient nature of space syntax, there still appears to be a theoretical gap in our thinking. It lies below the urban whole - emergence-convergence, foreground and background networks - and even below the urban pattern itself, i.e., Laws of Compactness and Linearity, spatioformal processes (Hillier, 1996; Hillier and Vaughn, 2007; Major, 2018). It deals with individual and collective actions in shaping and regulating the built environment. The former intimately ties to the generative effects of Hillier and Hanson's (1984) restricted random process following simple aggregation rules. The latter relates fundamentally to the emergence of town and urban planning as a distinct discipline and profession. Because of this, we hypothesize there is a need to introduce two additional laws of the urban object in the space syntax lexicon to address this perceived gap.

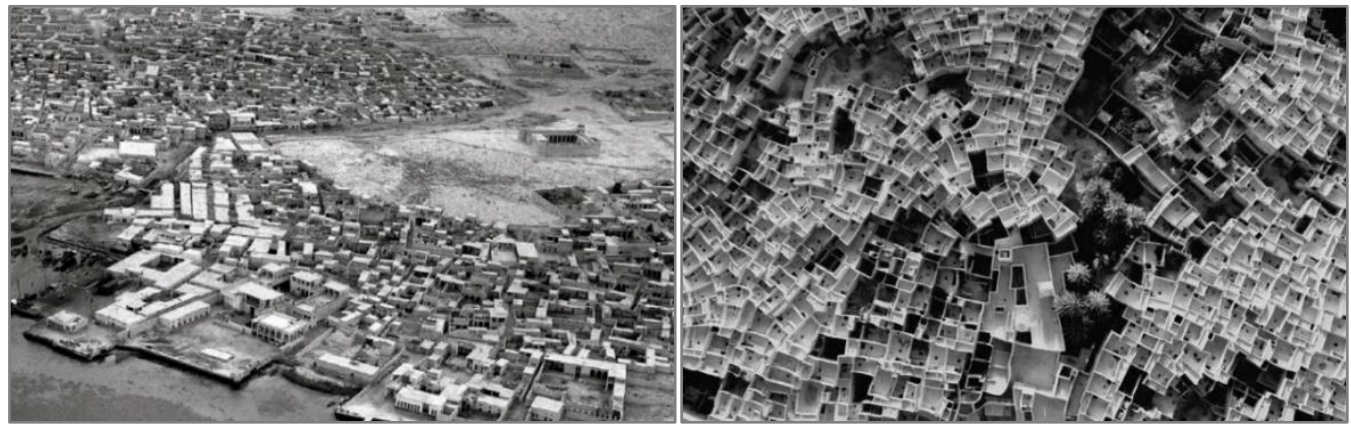

Figure 11 (left) Restricted random aggregation in giving rise to the early urban form of Doha, Qatar in 1947 and the (right) SubSaharan settlement of Ghadames, Libya in 2013 (Source: Embassy of Qatar in Bangkok, Thailand/Steinmetz, 2013). 
First, there is substantial historical evidence for a law of spatial conservation at work in the built environment. The law of spatial conservation pertains to the replication of local design moves. People will tend to replicate formal order ad infinitum in pursuit of their spatial strategies to conserve topo-metric characteristics in the absence of intervention. Hillier and Hanson's (1984) restricted random process - as Major (2018) describes it, restricted random aggregation - in settlements is a prominent feature of the law of spatial conservation (Figure 11).

A law of spatial conservation would provide a framework to explain why restricted random aggregation persists in some settlements for so long until some require extensive remedial topdown planning corrections such as Haussmann's introduction of boulevards in Paris in the late 19th century or elsewhere in the world (Karimi, 1998). It helps to explain Americans' extensive use of geometric order concepts in urban form, arising out of European Renaissance planning principles, for more than 350 years if we date from the founding of St. Augustine, Florida, in 1565 until the Euclid decision in 1926 (Major, 2018). ${ }^{3}$ It also illustrates Americans' persistence in building suburban sprawl for economic and regulatory reasons in the post-WW2 period, despite well-known problems that sprawl generates for the public health of individuals and communities (Katz et al., 1993; Major, 2018) (Figure 12).
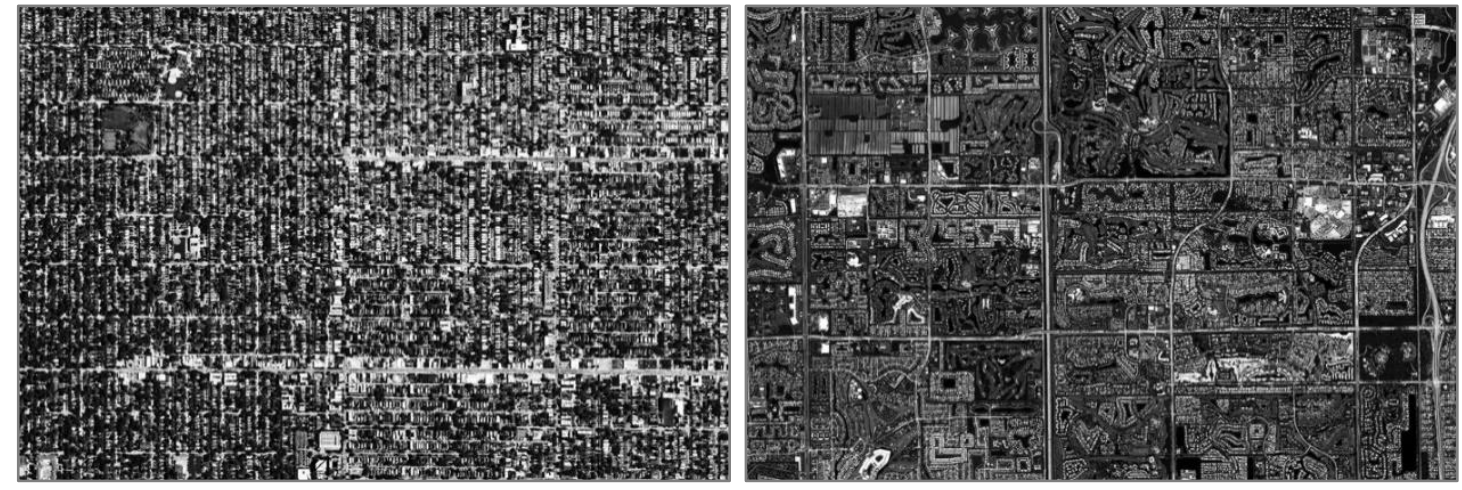

Figure 12 (left) The expansive orthogonal grid in the western suburbs of Chicago, Illinois USA in 2020 and the (right) proliferation of suburban sprawl in Boca Raton, Florida USA in 2019 (Source: Google Earth).

People will 'design along to get along' without intervention. The law of spatial conservation is the basis for town planning as a progressive endeavor or intervention where changing behavior is the goal for the good of society. In this sense, progressive means "happening or developing gradually or in stages," derived from the verb progredi from pro- meaning 'forward' plus gradi meaning 'to walk," which contributes to the Latin progressus meaning 'an advance' (Source: Oxford English Dictionary). It can be an actual or perceived good where subsequent events prove it either right or wrong over the long term. For example, Modernism manifestly represents a progressive movement in architecture and urban planning, even if subsequent events demonstrate critical flaws in Modernist planning principles (Jacobs, 1961). New Urbanism and its allies such as the Smart Growth Movement only represent the latest progressive attempt to address the underlying law of spatial conservation in changing individual and collective behavior of the good of society (Katz, 1993).

There is also evidence for a law of spatial optimization in the built environment. It indicates that people's use of space will tend to deviate marginally from local formal order to maximize most efficiently the topo-metric characteristics if allowed. It explicitly builds on Conroy-Dalton's (2001) ideas about angular choice and conservation of linearity in movement, namely that "people tend to conserve linearity through their routes with minimal angle deviation" (47.11). The most obvious evidence for this law at work in the urban environment is desire lines or paths, which we find ${ }^{3}$ Village of Euclid, Ohio v. Ambler Realty Co. (1926) was a landmark US Supreme Court decision establishing zoning a valid exercise of
police power under the US Constitution. 
worldwide. (Figure 13). It is an eroded path due to foot traffic, representing the shortest or most easily navigable route from one place to another in preference to - or the absence of - a designated alternative. The width and severity of erosion indicate foot traffic levels (Source: Wikipedia/Merriam-Webster Dictionary).

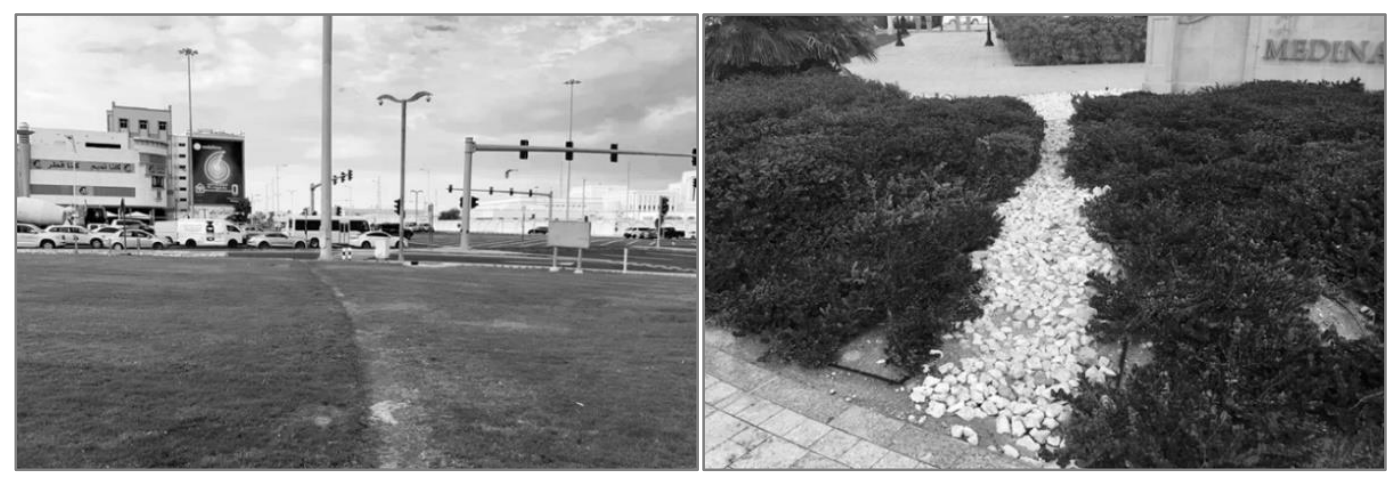

Figure 13 (left) Desire line cutting through the grass at the southern corner of the intersection of Ahmed Bin Ali Street and Mohammed Bin Thani Street near Hamad Medical City in 2019 and (right) remediation and attempt to deter use of a desire line by laying large landscaping stones in Medina Centrale at The Pearl-Qatar in 2018 in Doha, Qatar (Source: Authors).

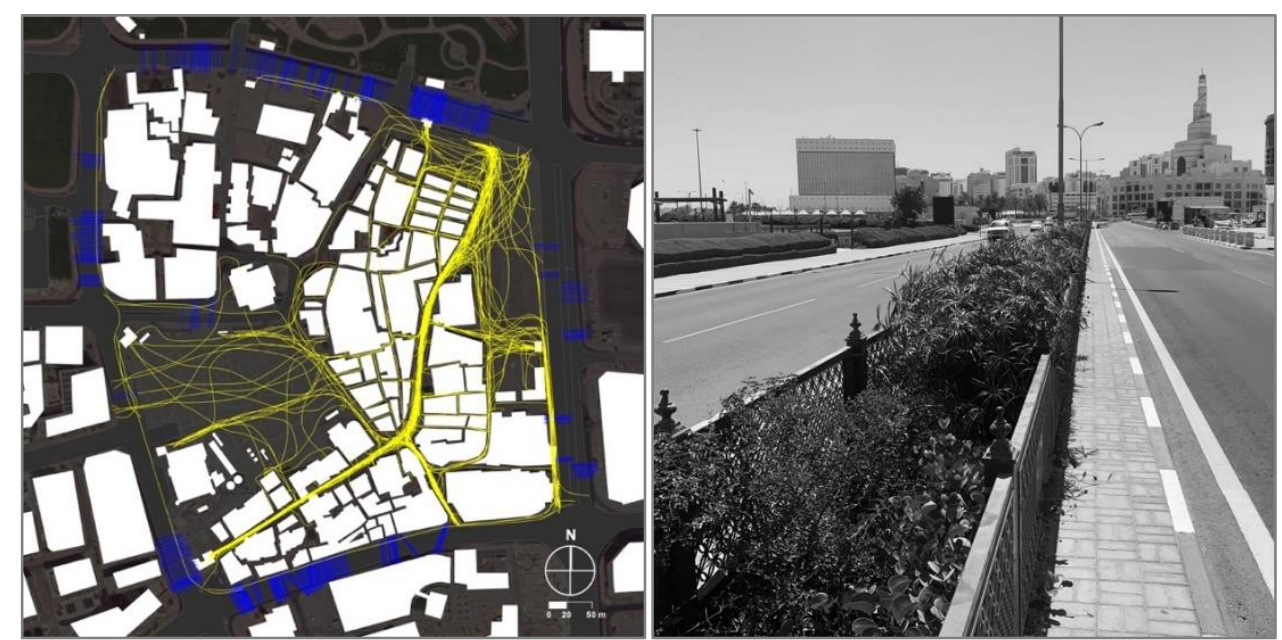

Figure 14 (right) All unprogrammed street crossings (in blue) of perimeter streets and movement patterns (in yellow) of a typical two hundred (200) people from the perimeter streets and underground infrastructure during the first 10 minutes of their visit or until they reached their initial destination, whichever came first, ${ }^{4}$ Doha and (left) public agency introduction of a double-row of fencing with landscaping to prevent unprogrammed street crossings (primarily women with children) from Souq Waqif (on the right) to Souq Waqif Park (on the left) later in 2020 (Source: UREP25-002-5-001).

The law of spatial optimization means 'people move along to get there easily.' It is the basis for design and planning as regressive control where controlling behavior is deemed necessary - or perceived as necessary, whether right or wrong over the long term - to protect society. The purpose of such control is to restrict people's ability to maximize their efficient use of space. It falls under the purview of public agencies' regulatory power to protect public safety. However, since the mid20th century, it has often been a thinly veiled disguise to keep vehicular traffic flows moving quickly and smoothly at the expense of human-scale urban design. Other examples of regulatory attempts to control spatial optimization are erecting fences down the middle of the road and threatened enforcement of draconian 'jaywalking' laws to compel people to use designated crosswalks instead of crossing streets where it is most convenient (Figure 14). In contrast, advocates of contemporary planning concepts such as Shared Space implicitly seek to capitalize on the potentials of the law of spatial optimization. They promote human-scale urban design for pedestrians while explicitly seeking to retard vehicular speeds and impacts of the private automobile on the public realm of our cities.

\footnotetext{
${ }^{4}$ Compiled during three months of fieldwork in Winter 2020-21 at Souq Waqif.
} 
Page | 11
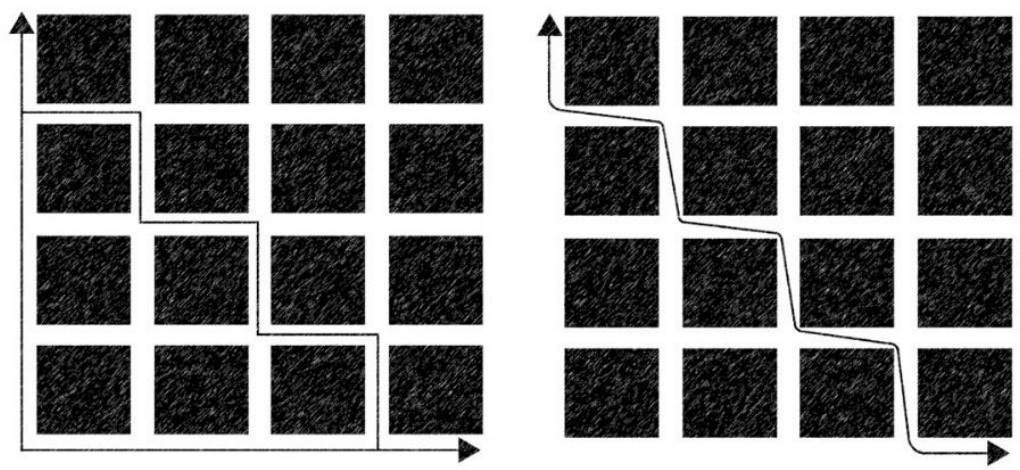

Figure 15 Orthogonal grid showing (left) two journeys from corner to the opposite corner of the layout with an equal trip distance of 950 feet ( 289.5 meters) via either the perimeter streets or cutting across the grid to approximate a diagonal and (right) a single journey with a trip distance of a little over 800 feet ( 244 meters) by approximating a diagonal through space of each street segment (Source: Authors)

\section{Geometry, Fractals, and Self-Similarity}

Spatial conservation and optimization are opposite sides of the same coin, which could co-exist under a broader umbrella of a law of spatial conservation since conservation occurs in spatio-formal and use terms. However, we distinguish between form and use (or function) in our definition to clarify and illustrate the different potentials of each. Nonetheless, form does not follow function nor vice versa. Form and function merely are.

We can conduct a thought experiment utilizing Hillier's Laws of Compactness and Linearity to demonstrate first, why people optimize their movement across space to diagonalize the urban grid and second, how this might play a role in giving shape to both the urban object and people's use of space. For this purpose, we utilize a simple orthogonal layout composed of lots one-eighth (1/8) of an acre in size measuring $55 \times 100$ feet or fifty-five hundred $(5,500)$ square feet (SF) where the street widths are fifty-five feet. In metric terms, it means the lots are marginally larger than 500 square meters $\left(\mathrm{m}^{2}\right)$, measuring about $16.75 \times 30.5$ meters, where the street widths are also 16.75 $\mathrm{m}$. The overall size of the layout is $1030 \times 950$ feet ( $314 \times 290$ meters) with a land area of $\sim 980,000$ SF ( 91,000 m2), or about 22.5 acres, excluding the perimeter streets.

Now, imagine two journeys available in the same layout from corner to the opposite corner as more or less represented in the least line axial map (Figure 15, left). The basis of the first journey is the most efficient trip from origin to destination. Efficiency in this sense means the most optimal, feasible route utilizing the fewest changes of direction. In this case, one change of direction using the perimeter streets. The basis of the second journey approximates a diagonal from origin to destination. In this case, the most optimal approximation for a diagonal across the layout requires a minimal seven changes of direction. The approximate length of both journeys is nine hundred and fifty feet $(289.5 \mathrm{~m}) .^{5}$ Based on the least line axial structure, approximating a diagonal across the layout is seven times less efficient in terms of direction changes than using the perimeter streets for covering the same distance.

At least, this is what Minkowski's (1910) Taxicab or Manhattan geometry would tell us (Conroy, 2001). Taxicab or Manhattan geometry is an absolute coordinate system devising a new metric where the distance between two points is the difference ('as the crow flies') of their Cartesian coordinates. The latter name (Manhattan geometry or distance) alludes to the gridded layout of streets on the island of Manhattan, which causes the shortest path of a car between two intersections in the borough to possess a length equivalent to the intersections' distance in taxicab geometry. Perhaps it is telling that the rise of the use of Manhattan distance in town planning and

\footnotetext{
${ }^{5}$ The distance for the route approximating a diagonal across this layout is actually approximately twenty-five ( 25$)$ feet or $7.5 \mathrm{~m}$ longer due to centrally locating the journey in the space of each street segment.
} 
urban transportation coincides with the rise of the private automobile and regulatory enforcement of street sections, which confine pedestrians to the edges of streets.

However, pedestrians move across the urban grid every day while in movement from here to there everywhere in the world. The reason is quite simple; people utilize any feasible opportunities to do the same within the space of the street segment itself to converse distance and optimize their use of space. The most efficient journey conserving distance in movement through this layout transverses segments at about a 150 angle with the cardinal directions, or right and left turns occurring at 105 rather than a 90 을 angle. In effect, the pedestrian reads the spatial structure in terms of visual integration for the closest approximation of a diagonal at the global and local scale of the journey, i.e., across the grid and within the street space itself, respectively. The distance of this journey is a little over eight hundred (800) feet. Even though approximating a diagonal still involves seven directional changes, the journey is twenty percent (20\%) more efficient in conserving distance than using the perimeter streets.

The most efficient journeys from all spatial locations to all others in the layout tend to pass through the center and radiate outward from there to the edges (Hillier, 1996; Major, 2018). The larger the block, then the less acute is the available angle for pedestrians to transverse a street segment on a diagonal, therefore the amount of distance conserved is corresponding less. It seems important. Jacobs (1961) argues smaller blocks are better for pedestrian activity and Whyte (1988) concurs with her assessment, "the tight grid and short blocks may be rigid but that pattern maximizes pedestrian activity" (337). It appears more accurate to say that compactness rather than smallness is better for pedestrian activity.

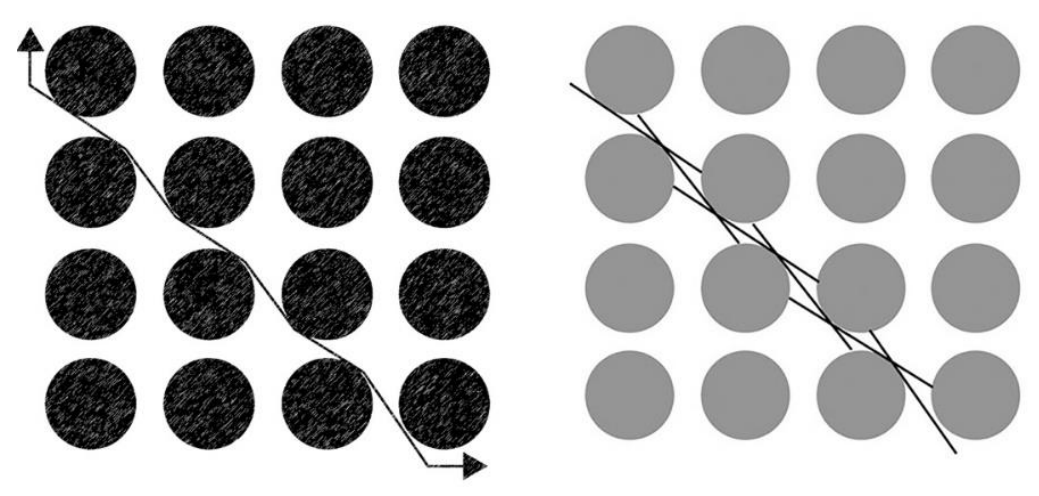

Figure 16 - Orthogonal grid showing experiment (left) optimizing a journey across the grid using circular-shaped blocks and (right) the axial structure of such a trip (Source: Authors).

Another simple experiment demonstrates this when we replace the square-shaped blocks in the layout with circular ones, i.e., the most internally integrating shape according to Hillier (1996), providing a minimum perimeter surface area for each urban block (Figure 16, left). 6 The apex of the circumference defines the most optimal visual lines of sight in the layout. For a journey from one corner to the opposite across the layout, it is possible to approximate a diagonal from origin to destination more closely. Seven direction changes are still required, but they are more gradual than within 15o of a right angle. The most efficient journey to conserve distance transverses at a 350 angle through each street segment with a trip distance of seven hundred twenty-five (775) feet or 236 meters. Using circular blocks makes the journey ten percent $(+10 \%)$ more efficient for conserving distance than the layout with square-shaped blocks and thirty percent $(+30 \%)$ more efficient than utilizing perimeter streets with only one change of direction. Of course, circular blocks are not practical in terms of the most optimal use of the land for lot subdivision. The potential for

\footnotetext{
${ }^{6}$ Triangular-shaped blocks provide a minimal perimeter surface but defined within the same bounds, it would also lose a significant amount of buildable area. A layout based on triangular-shaped blocks would be diagonal streets in one dimension and straight streets in the other as well as for the perimeter streets if bound remains in the the shape of a rectangle.
} 
greater efficiency in terms of movement by using circular blocks sacrifices other efficiencies afforded by rectangular blocks, i.e., surveying, vertical construction, etc.

The least line axial structure illustrates this journey (Figure 16, right). It is not an accident that it begins to approximate the typical structure of principal streets in a deformed grid layout, i.e., within a 15o angle of a direct continuation according to Hillier (1999a) but 20 in the case of this layout.

Page | 13 North London provides a perfect example of how the law of spatial optimization can find its way into shaping urban form (Figure 17). A comparison of three radial trips out of central London to the northwest edges of the city - sequence of Camden Road/Chalk Farm Road/Belsize Park Road/ Haverstock Hill/Hampstead High Street/Heath Street, Finchley Road, and Edgeware Road - suggest spatial optimization at work as axial lines get longer and straighter with overall size over time. Many short axial lines ( 15 , dependent on where we begin the journey) compose the first radial route. $A$ moderate number ( $\sim 9$, again depending on where we start) form the second. Only a few axial lines $(\sim 4)$ compose the last, i.e., Edgeware Road. However, all three perform the same functional role in the emergent spatial structure of Greater London. Taxicab or Manhattan distance also begins to better approximate actual Cartesian distances with the more significant formal order and vice versa.

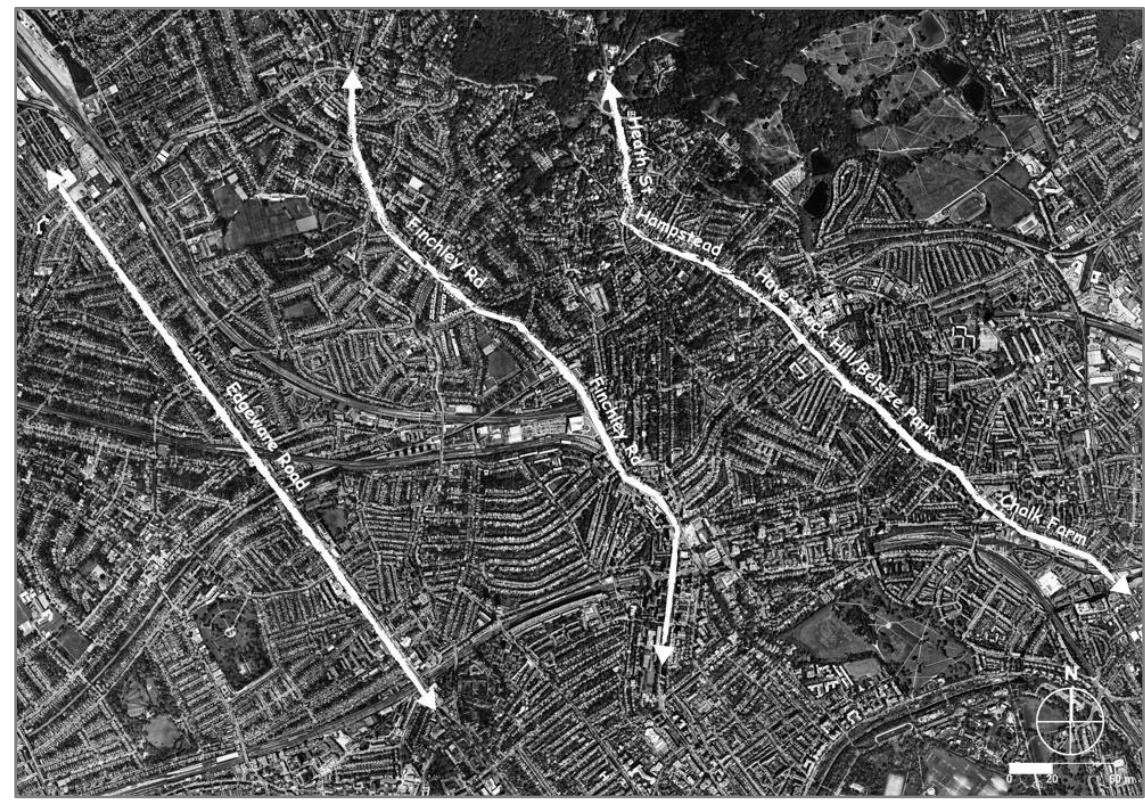

Figure 17 - Satellite view from $5 \mathrm{~km}$ showing the compositional relationship of the (from left to right) Edgeware Road, Finchley Road, and Health Street/Hampstead High Street/Haverstock Hill/Belize Park Road/Chalk Farm Road eventually to Camden High Street in north London, United Kingdom in 2021 (Source: Authors/Google Earth).

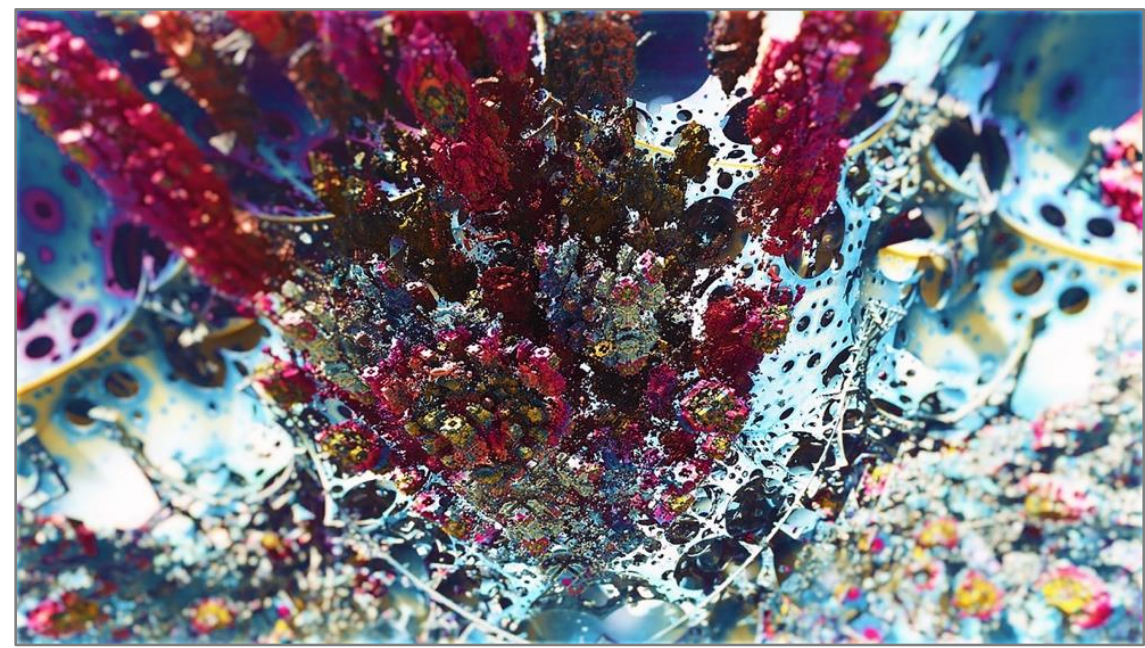

Figure 18 - Fractal city (Source: Pixabay). 
Spatial conservation and optimization seem to offer a firmer theoretical foundation linking space syntax theory with the work of Batty (2005) and others about the fractal nature of cities (Batty \& Longley, 1984). They argue that all cities have a fractal dimension (Figure 18). Fractals are infinitely complex patterns that are self-similar across different scales, created by repeating a straightforward process over and over in an ongoing feedback loop such as Hillier and Hanson's (1984) restricted random aggregation (Major, 2018). However, a law of spatial conservation as an aspect of people designing along to get along in their spatio-formal strategies also describes the fractal generation of urban form. It incorporates repetitive processes using only a few rules, some articulated in ethnic-specific terms, such as additional rules about the placement of front doors and windows overlooking yards in the experience of Islamic settlements (Tannous, 2020; Major \& Tannous, 2020; Khan et al., 2021; Tannous et al., 2021). The fractal dimension is an aspect of selfsimilarity characterizing all settlements across different scales. It tends to persist even as the scale of the urban pattern upsizes during the evolution of city growth (Batty and Longley, 1994; Carvalho and Penn, 2004; Shpuza, 2014). It is unsurprising. Due to the human genotype, all cities are principally composed of blocks and streets as the material realization of Hillier's principles of centrality and linearity in the urban pattern. Spatial conservation and optimization are fundamental aspects of each in formal and spatial terms. Two sides of the same coin spent in giving shape to and our everyday use of the urban object.

The implications are many. Recognition of the resilience of local design moves in bottom-up processes in a law of spatial conservation might indicate a greater need for empathy about the instrumental power of the self-generating mechanisms of the urban object. In some cases, this might mean professionals allowing time before intervening, so such mechanisms to evolve into a state of maturity. On the other hand, minimal angle deviation to converse linearity in movement through built space is a well-established principle of space syntax and its measurement toolkit. Embedding this principle within a general law of spatial optimization might allow professionals a better framework for capitalizing on these spatial potentials in design and planning. Space syntax consultants already do this to a large degree in crafting the form and function of the built environment in real-world projects. However, articulating a law of spatial optimization on such terms removes the issue from the purview of design intuition - even ones based on space syntax to practical application about what people want to do in their built environments if allowed. It might also bring into doubt the wisdom of road centerline mapping since it favors separated road sections and promotes mechanized travel by default, like the coordinate concept of Manhattan distance itself. Such a re-think might be necessary if we want to truly achieve human-centered design in this cultural milieu, which values other 'things' above that of the people living in our built environments.

\section{Conclusion}

We attempted to cover a substantial amount of theoretical ground concisely, including definitions of resilience in the field, the resilient nature of space syntax as a method, and the essential components of theoretical thinking to arise from the space syntax research program over the last forty years. On this basis, the paper offered a new hypothesis about laws of spatial conservation and optimization at work in the built environment. We argued the former provides an essential link to Batty and Longely's (1994) notions of fractal cities based on Carvalho and Penn's (2004) concept of self-similarity in settlements. The latter explicitly builds on Conroy-Dalton's (2001) ideas about angularity and conservation of linearity in movement. Both provide the conceptual framework for the progressive and regressive nature of town planning as a discipline worldwide today. We briefly illustrated evidence for our arguments based on replication of previous space syntax findings in the urban spatial network of Metropolitan Doha. We also presented new research findings drawing on the history, spatial structure, neighborhood logic, and pattern movement patterns in that city. The paper concluded by arguing that conservation-optimization provides a critical 'glue' to unify several concepts floating within and surrounding space syntax and town planning. 


\section{Funding}

Portions of the research in this paper involving the Souq Waqif and the space syntax model of Metropolitan Doha was supported in part by an Undergraduate Research Experience Program (UREP) grant from the Qatar National Research Foundation (QNRF) (Grant ID: UREP25-002-5-001) and internal grants of Qatar University (Grant IDs: QUSDCENG-2018/2019-4 and QUCG-CENG-20/21-1). The findings achieved herein are solely the responsibility of the authors.

\section{Acknowledgements}

The title of this paper is an explicit reference to Jacobs' (1961) famous phrase that cities happen to be problems in organized complexity in the Final Chapter of The Death and Life of Great American Cities (New York: Penguin Books).

Figure-ground representations of one $\mathrm{km}^{2}$ in Muscat, Oman and Doha, Qatar by Heba O. Tannous as part of her MUPD Thesis (Tannous, 2020). Authors modified the figure-ground representations in Figure 6 originally by undergraduate students on the ARCT 210 course in the Department of Architecture and Urban Planning, College of Engineering at Qatar University in Fall 2017, 2018, and 2021 including: Najla Al-Mohannadi (Alexandria, Egypt); Alya Al-Marri (Amman, Jordan); Shams A. Allawi and Fatima K. Al-Hayder (Beirut, Lebanon); Farsana Abdulla Aravassery (Cairo, Egypt); Saaeda Al-Bader (Casablanca, Morocco); Hawra A. Moosawi and Marwa A. Elaradi (Damascus, Syria); Fatima Al-Jaeri (Dubai, UAE); Aisha Alahbabi (Istanbul, Turkey); Reem Taher and Hanan Alemadi (Jeddah, Saudi Arabia); Dhabya Al-Naimi (Jerusalem); Maryam AlSubaey and Aljazi Al-Marri (Kuwait City, Kuwait); and, Maryam Mohammed (Riyadh, Saudi Arabia).

\section{References}

Batty, M: (2005). Cities and Complexity: Understanding Cities with Cellular Automata, Agent-Based Models, and Fractals. Cambridge. Massachusetts: MIT Press.

Batty, M; Longley, P; (1994) Fractal Cities: A Geometry of Form and Function. Cambridge, Massachusetts: Academic Press.

Baudrillard, J; (1968). Le Système des objets (The System of Objects) (9 $9^{\text {th }}$ Edition, Trans. J. Benedict). London/New York: Verso.

Benedikt, ML; (1979). To Take Hold of Space: Isovists and Isovists Fields. Environment and Planning B: Planning and Design, 6: 47-66.

Carvalho, R; Penn, A; (2004) "Scaling and universality in the micro-structure of urban space", Physica A, 32: 539-547.

Conroy, R; (2001) Spatial Navigation in Immersive Virtual Environments. PhD Thesis, The Bartlett School of Graduate Studies, University of London.

Conroy-Dalton (2001) The Secret is to Follow Your Nose: Route Path Selection and Angularity. Proceedings of the 3rd International Space Syntax Symposium (Eds. Peponis J., Wineman, J., and Bafna, S.). University of Michigan, pp. 47.1-47.14. ISBN: 1-891197-18-5.

Davoudi, S; (2012). Resilience: A Bridging Concept or a Dead End? Planning Theory \& Practice. 13(2): 299333.

Hanson, J; (1998). Decoding Homes and Houses. Cambridge: Cambridge University Press.

Holling, CS; (1973). Resilience and stability of ecological systems. Annual Review of Ecological Systems, 4: $1-23$.

Holling, CS; (1986). The resilience of terrestrial ecosystems: Local surprise and global change. Sustainable Development of the Biosphere (WC Clark \& RE Munn, Eds.). London: Cambridge University Press, 292317.

Hillier, B; Vaughan, L; (2007). The City as One Thing. Progress in Planning, 67(3): 205-230.

Hillier, B; (2002). "A Theory of the City as Object: or, How Spatial Laws Mediate the Social Construction of Urban Space," Urban Design International, 7: 153-179.

Hillier, B; (1999b). "Centrality as a Process: Accounting for Attraction Inequalities in Deformed Grids," Urban Design International, 4: 107-127. 
Hillier, B; (1999a). "The Hidden Geometry of Deformed Grids: or, Why Space Syntax Works When It Looks As Though It Shouldn't," Environment and Planning B: Planning and Design, 26(2): 169-191.

Hillier, B; (1996). Space is the Machine: A Configurational Theory of Architecture. Cambridge: Cambridge University Press.

Hillier, B: Penn, A; Hanson, J; Grajewski, T; Xu, J; (1993) Natural Movement: or Configuration and Attraction in Urban Pedestrian Movement. Environment and Planning B: Planning and Design, 20: 29-66.

Hillier, B; (1989). The Architecture of the Urban Object. Ekistics, 334/335: 5-20.

Hillier, B; Burdett, R; Peponis, J; Penn, A; (1987b). Creating Life: Or Does Architecture Determine Anything? Architecture et Comportement/Architecture and Behaviour, 3(3): 233-250.

Hiller, B; Hanson, J; Graham, H; (1987a). Ideas are in Things: An Application of Space Syntax Method to Discovering Housing Genotypes. Environment and Planning D: Planning and Design, 14: 363-385.

Hillier, B; Hanson, J; (1984). The Social Logic of Space. Cambridge: Cambridge University Press.

Jacobs, J; (1961). The Death and Life of Great American Cities. New York: Penguin Books.

Katz, P; (1993). The New Urbanism: Toward an Architecture of Community. New York: McGraw-Hill Education.

Karimi, K; (1998). Continuity and Change in Old Cities: An Analytical Investigation of the Spatial Structure in Iranian and English Historic Cities Before and After Modernisation. Ph.D. Thesis. Copies available from Senate House, University of London.

Khan, AH: Major, MD; Tannous, HO; (2021). "Tradition, Transformation, and Re-creation in Two Marketplaces: Souq Al Wakrah and Souq Waqif, Qatar," Habitat International, 116, 102438, ISSN 01973975, https://doi.org/10.1016/j.habitatint.2021.102438.

Lefebvre, H; (1974). La production de l'espace (The Production of Space), Paris, France: Anthropos. Translation and Précis

Leroi-Gourhan, A; (1964). Geste Et La Parole (Gesture and Word)-Tome 1 (Le) (Collections SciencesSciences Humaines). Paris, France: Albin Michel.

Leroi-Gourhan, A; (1945). L'Homme et la matière (Man and Matter). Paris, France: Albin Michel.

Leroi-Gourhan, A; (1943). Milieu et techniques (Environment and Techniques). Paris, France: Albin Michel.

Major, MD; Tannous, HO; Aravassery, FA; Mohammed, HM; Shakerpoor, GS: Ellath, L; (2021) "Space, Time And Natural movement in old Doha (STAND): The morphological case of Souq Waqif," Final Report: UREP25-002-5-001, Qatar National Research Foundation, 1 July 2021, 26 pp.

Major, MD; Donegan, L; (2020). "Back to Basics: Generalising Space Syntax Principles for Undergraduate Students," China Journal of Urban Design. Beijing: Tsinghua University Press, November, 5(31), pp. 623. http://urbanism.com.cn/EN/abstract/abstract153691.shtml.

Major, MD; (2020). "The Good, the Bad, and the Ugly: Historic Design Lessons and Contemporary Planning Failures in Savannah, Georgia USA," 5th ISUFitaly International Conference: Urban Substrata \& City Regeneration: Morphological Legacies and Design Tools Proceedings (G. Strappa, P. Carlotti, M. leva, Eds. with F. D. De Rosa, A. Pusceddu), 19-22 February 2020, Rome, Italy: Sapienza Università di Roma and International Seminar on Urban Form-Italian Network (U+D Edition), ISBN 978-88-941188-8.9, 177-189. Available at: https://www.urbanform.it/app/download/15929081722/ISUFitaly+Roma+2020Proceeding.pdf.

Major, MD; Tannous, HO; (2020). "Form and Function in Two Traditional Markets of the Middle East: Souq Mutrah and Souq Waqif," Special Issue on Space Syntax Theory, Methods and Applications, Sustainability: Sustainable Urban and Rural Development, 12(17), 7154, doi:10.3390/su12177154, https://www.mdpi.com/2071-1050/12/17/7154.

Major, MD; Mirincheva, V; Tannous, HO; (2019) "Urban Transformations: From restricted random aggregation to designed cultural intent in Middle Eastern cities" (in Chinese and English), China Journal of Urban Design. Beijing: Tsinghua University Press, 5, 2019: 34-49, http://urbanism.com.cn/EN/abstract/abstract153502.shtml\#1.

Major, MD; Al-Nabet, SF; (2018). Buildings Don't Bounce: The Design Paradox of Urban Resilience. New Urban Research Session, Congress for New Urbanism 26, 16-19 May 2018, Savannah, Georgia USA, https://www.cnu.org/new-urban-research/papers.

Major, MD; (2018). The Syntax of City Space: American Urban Grids. New York/London: Routledge.

Major, MD; (2015). "The Invention of a New Scale: the paradox of size and configuration in American cities" Journal of Space Syntax. University College London, 6(1), pp. 170-191. ISSN: 2044-7507.

Major, MD; (2013). "The City's Essential DNA: Formal design and spatial processes in the urban pattern," Journal of Space Syntax. University College London, 4(1), pp. 160-164. ISSN: 2044-7507.

Minkowski, H; (1910). Geometrie der Zahlen (in German). Leipzig and Berlin: R. G. Teubner.

Penn, A; Hillier, B; Banister, D; Xu, J; (1998). Configurational Modeling of Urban Movement Networks. Environment and Planning B: Planning and Design, 25: 59-84.

Salama, A; Wiedmann, F; (2013). Demystifying Doha: On Architecture and Urbanism in an Emerging City. New York: NY: Ashgate Publishing/Routledge. 
Shpuza E; (2014). "Allometry in the Syntax of Street Networks: Evolution of Adriatic and Ionian Coastal Cities 1800-2010," Environment and Planning B: Planning \& Design, 41: 450-471.

Steinmetz, G; (2013). "Photo of the Day," National Geographic Magazine, 27 March 2013. Accessed: 14 September 2021 at https://www.nationalgeographic.com/photo-of-the-day/photo/ghadames-aerialsteinmetz.

Tannous, HO; Major, MD; Al-Obaidan, M; (2021). "Past Traditionalism, Present Modernism, and the New Qatari Regionalism: Architectural Vocabularies over Time in Qatar," 18th Annual International Architectural Humanities Research Association (AHRA) Conference, 11-13 November 2021, Loughborough University, United Kingdom.

Tannous, HO; Major, MD; Furlan, R; (2021). Accessibility of Green Spaces in a Metropolitan Network: Using Space Syntax to Objectively Evaluate the Spatial Locations of Parks and Promenades in Doha, State of Qatar. Urban Forestry \& Urban Greening, 58(2021), https://doi.org/10.1016/j.ufug.2020.126892.

Tannous, HO; (2020). Traditional Markets in Context: A Morphological Comparison of Souq Waqif in Doha, Qatar and Mutrah Souq in Muscat, Oman. MUPD 760 Thesis Focus on Urban Design, copies available from the authors and Qatar University Library.

Turner, A; Doxa, M; O’Sullivan, D; Penn, A; (2001). From Isovists to Visibility Graphs: A Methodology for the Analysis of Architectural Space. Environment and Planning B: Planning and Design, 28(1): 103121.

van Nes, A; Yamu, C; (2021). Introduction to Space Syntax in Urban Studies. Cham, Switzerland: Springer.

\section{Resume}

Dr. Mark David Major, AICP, CNU-A is an Assistant Professor of Architecture and Urban Design at Qatar University in Doha. He has three decades of experience in architecture, urban design and planning, real estate development, and business in Europe, United States, and the Middle East. Mark is the recognized Founder of International Space Syntax Symposia and the leading American expert on space syntax. He is the author of The Syntax of City Space: American Urban Grids (2018, Routledge Books) and the Poor Richard series (Forum Books, 2012, 2014, and 2017) of almanacs for architects and planners.

Raya M. Atour is an architectural engineer. She is a current master's student in Department of Architecture and Urban Planning at Qatar University. Raya graduated with a BSC in Architectural Engineering from the University of Sharjah in 2020. Previously, she was also a student at the IMS Bauhaus Institute in Dessau, Germany. Her education in various places including Jordan, United Arab Emirates (UAE), Germany, and Qatar has broadened her research interests. She won second-place in the UOS Innovation Week Competition held at Expo Sharjah 2017. Raya initiated and worked on an architectural project at the Sharjah Academy for Astronomy, Space Sciences, and Technology in UAE, where she worked as a project leader and research assistant. Her interdisciplinary research interests include sustainable development, architectural theory, and sociology.

Heba O. Tannous is a Research Associate in the Department of Architecture and Urban Planning, College of Engineering, at Qatar University in Doha. She is also a lecturer at Virginia Commonwealth University, School of Arts in Qatar. She holds a Master of Science in Urban Design and Planning from Qatar University and a Bachelor of Arts in Architectural Design from Eastern Mediterranean University in North Cyprus. Palestinianborn and raised in Jerusalem, she won Third Prize in the RIBA Cityscape Intelligence Sketchbook-Culturally Significant Vernacular Architecture in the Gulf competition in 2020. Heba is co-author on several papers including "Urban Transformations: From restricted random aggregation to designed cultural intent in Middle Eastern cities" presented at the 12th International Space Syntax Symposium in Beijing, China. Her recent activities include the participation in Urban Thinkers Campus Conference with the UN Habitat and ISOCARP, and MENA SS webinars with research topics not limited to green urbanism, traditional souqs, accessibility, and urban morphology. 